\title{
Comparison of prophylactic higher fluence corneal cross-linking to control, in myopic LASIK, one year results
}

This article was published in the following Dove Press journal:

Clinical Ophthalmology

27 November 2014

Number of times this article has been viewed

\section{Anastasios John \\ Kanellopoulos ${ }^{1,2}$ \\ George Asimellis' \\ Costas Karabatsas'}

'LaserVision.gr Clinical and Research Eye Institute, Athens, Greece; ${ }^{2} \mathrm{New}$ York University Medical School, New York, NY, USA
Correspondence: A John Kanellopoulos Laservision.gr Eye Institute, 17 Tsocha Street, Athens, II 5 2I, Greece

Tel +30 210 7472777

Fax +30210747 2789

Email ajk@brilliantvision.com
Purpose: To compare 1-year results: safety, efficacy, refractive and keratometric stability, of femtosecond myopic laser-assisted in situ keratomileusis (LASIK) with and without concurrent prophylactic high-fluence cross-linking (CXL) (LASIK-CXL).

Methods: We studied a total of 155 consecutive eyes planned for LASIK myopic correction. Group A represented 73 eyes that were treated additionally with concurrent prophylactic highfluence CXL; group B included 82 eyes subjected to the stand-alone LASIK procedure. The following parameters were evaluated preoperatively and up to 1-year postoperatively: manifest refractive spherical equivalent (MRSE), refractive astigmatism, visual acuity, corneal keratometry, and endothelial cell counts. We plotted keratometry measurements pre-operatively and its change in the early, interim and later post-operative time for the two groups, as a means of keratometric stability comparison.

Results: Group A (LASIK-CXL) had an average postoperative MRSE of $-0.23,-0.19$, and $-0.19 \mathrm{D}$ for the 3-, 6-, and 12-month period, respectively, compared to $-6.58 \pm 1.98 \mathrm{D}$ preoperatively. Flat keratometry was $37.69,37.66$, and $37.67 \mathrm{D}$, compared to $43.94 \mathrm{D}$ preoperatively, and steep keratometry was $38.35,38.36$, and $38.37 \mathrm{D}$, compared to $45.17 \mathrm{D}$ preoperatively. The predictability of Manifest Refraction Spherical Equivalent (MRSE) correction showed a correlation coefficient of 0.979 . Group B (stand-alone LASIK) had an average postoperative MRSE of $-0.23,-0.20$, and $-0.27 \mathrm{D}$ for the 3-, 6-, and 12-month period, respectively, compared with $-5.14 \pm 2.34 \mathrm{D}$ preoperatively. Flat keratometry was $37.65,37.89$, and $38.02 \mathrm{D}$, compared with $43.15 \mathrm{D}$ preoperatively, and steep keratometry was $38.32,38.57$, and $38.66 \mathrm{D}$, compared with 44.07 D preoperatively. The predictability of MRSE correction showed a correlation coefficient of 0.970 . The keratometric stability plots were stable for the LASIK CXL group and slightly regressing in the standard LASIK group, a novel stability evaluation metric that may escape routine acuity and refraction measurements.

Conclusion: Application of prophylactic CXL concurrently with myopic LASIK surgery appears to contribute to improved refractive and keratometric stability compared to standard LASIK. The procedure appears safe and provides a new potential for LASIK correction.

Keywords: myopic LASIK regression, femtosecond myopic LASIK, LASIK-CXL, LASIKXtra, high myopia, accelerated high-fluence collagen cross-linking

\section{Introduction}

Laser-assisted in situ keratomileusis (LASIK) is the most common form of refractive surgery, ${ }^{1,2}$ offering predictable and stable refractive and visual outcomes. ${ }^{3}$ Specifically, in correcting moderate to high myopia (equal or more than $-6.00 \mathrm{D}$ in the least-minus meridian), ${ }^{4,5}$ there have been reports in the past indicating significant long-term regression. ${ }^{6-8}$ The work by Alió et $\mathrm{al}^{9}$ reported that $20.8 \%$ of high myopia cases required 
retreatment because of over- or undercorrection, or regression. Other studies have shown that the risk of regression may be between $5 \%$ and $27 \% .^{10}$

Our team's experience with high myopia LASIK correction suggests a slight $(0.5 \mathrm{D})$ long-term postoperative corneal steepening trend. ${ }^{11}$ This was the motivation behind attempting to apply prophylactic in situ cross-linking (CXL) on the stromal bed, concurrently with the LASIK procedure, particularly in high-myopic eyes with thin residual stroma and in younger patients who may not yet have exhibited ectasia risk factors. ${ }^{12,13}$ The application aims to enhance corneal rigidity and thus reduce the possibility of long-term myopic shift. ${ }^{1-16}$

This study aimed to investigate potential differences in safety and efficacy, as well as in the refractive and keratometric results of myopic LASIK utilizing the Wavelight ${ }^{\circledR}$ FS200 Femtosecond Laser (Alcon Laboratories Inc, Fort Worth, TX, USA) and the Wavelight ${ }^{\circledR}$ EX500 Excimer Laser (Alcon Laboratories Inc) refractive surgery platforms. The study evaluated 1-year refractive and keratometric results from two groups, a "LASIK-CXL" and a standalone "LASIK" group, in which no concurrent CXL was applied.

\section{Materials and methods}

This prospective, observational, longitudinal study received approval by the Ethics Committee of LaserVision.gr Eye Institute and adhered to the tenets of the Declaration of Helsinki. Informed written consent was provided and documented from each subject at the time of the first study visit. The patients selected to receive the LASIK-CXL treatment were comprehensively informed of the benefits and risks involved in this procedure (which is Conformité Européene [CE]-marked in Europe).

\section{Inclusion and exclusion criteria}

A total of 155 consecutive patients enrolled for LASIK correction of primary myopia constituted this study. Group A (LASIK-CXL) consisted of 73 eyes in which concurrent prophylactic CXL was applied, while group B consisted of 82 eyes in which no such additional intervention was implemented (stand-alone LASIK). Only one eye was randomly selected (using randomization tables) from each patient to be included in the study, all of whom received bilateral surgery. All operations were performed by the same surgeon (AJK).

The inclusion criteria comprised: no other previous ocular surgery, documented refractive stability for at least 3 years, and discontinuation of contact lens use for at least 2 weeks.
Prior to intervention, a complete preoperative ophthalmologic evaluation ensured there was no present or past ocular pathology other than refractive error. The exclusion criteria comprised: systemic or ocular diseases, eyes with history of corneal dystrophy or herpetic eye disease, topographic evidence of ectatic corneal disorder, epithelial warpage from contact lens use, corneal scarring, glaucoma, severe dry eye, and collagen vascular disease.

As per our clinical protocol for the last 6 years, in this study, the LASIK treatments for myopia were allocated to include LASIK-CXL if the patient had either of the following preoperative measurements: mean manifest refraction spherical equivalent (MRSE) over $-5.00 \mathrm{D}$ or keratometric astigmatism over 1.50 D on Scheimpflug-derived simulated keratometry, or predicted residual postoperative stromal thickness less than $330 \mu \mathrm{m}$. No similar restrictions were applied in the inclusion criteria for the standard LASIK group B, other than applying it for myopia not exceeding $-10.00 \mathrm{D}$.

\section{Surgical technique}

In both groups, the FS200 Femtosecond Laser was employed to provide a corneal flap of $110 \mu \mathrm{m}$ thickness and $8.00 \mathrm{~mm}$ diameter. ${ }^{17}$ The average pulse energy for the flap bed cut was $0.8 \mu \mathrm{J}$, the side cut angle was $70^{\circ}$, and the hinge position was superior. For the bed cut, the spot and line separations were $8 \mu \mathrm{m}$. For the side cut, the spot separation was $5 \mu \mathrm{m}$ and line separation $3 \mu \mathrm{m}$. The myopia ablation (6 $\mathrm{mm}$ to $6.50 \mathrm{~mm}$ ablation zone diameter) treatment was accomplished with the EX500 Excimer Laser. ${ }^{18}$

Specifically for the LASIK-CXL, after the excimer laser ablation, and with the flap folded onto itself and protected with a dry Wexel sponge, one drop of Vibex Rapid ${ }^{\mathrm{TM}}$ (Avedro, Inc., Waltham, MA, USA), consisting of $0.10 \%$ saline-diluted riboflavin (a very slightly hypotonic solution, mixed with hydroxypropyl methylcellulose [HPMC], a dextran substitute), was placed on the exposed stromal bed afforded by the open LASIK flap and carefully spread over the bed area with an irrigating cannula for 60 seconds.

It is important to avoid riboflavin immersion of the flap and its hinge - for this purpose, the flap was protected, while remaining in a folded shape, as indicated in our earlier work. ${ }^{14}$ The reason for this is to inhibit flap collagen CXL. However, a small amount of riboflavin absorption, and thus CXL, will inevitably occur as a result of osmosis during the (however short) ultraviolet A (UVA) exposure as the flap is in contact with the riboflavin-soaked stroma. One has to consider the following aspects: a riboflavin-presoaked flap will participate strongly in the UVA absorption (as it precedes 
the residual stroma along the illumination propagation path); however, it will not contribute any further to the corneal biomechanical stability and may negatively affect the postrefractive outcome, given that a $110 \mu \mathrm{m}$ thick flap has perhaps only a $60 \mu \mathrm{m}$ stromal (collagen) content. The application of CXL to such a thin stromal layer may lead to undesirable flap shrinking. Regarding collateral benefits, a "CXL" flapstromal interface might positively affect flap adherence. ${ }^{19}$

Following stromal soaking, the flap was properly repositioned into place and the residual riboflavin-irrigated; then a UVA fluence of $30 \mathrm{~mW} / \mathrm{cm}^{2}$ was applied for 80 seconds (total energy $2.4 \mathrm{~J} / \mathrm{cm}^{2}$ ), provided by the $\mathrm{KXL}^{\circledR} \mathrm{CXL}$ system (Avedro, Inc.).

The selection of the UV irradiation parameters (fluence and exposure time) was influenced by the following considerations: (a) provision of about half of the full "treatment" energy in comparison with the traditional CXL protocol, (b) minimization of UVA exposure in order to constrain CXL within the overlaying flap, and (c) minimization of flap dehydration and possible shrinkage.

The superficial application of UVA following the in situ instillation of riboflavin was selected taking into account the following aspects:

- Application of CXL to the underlying stroma increases flap dehydration and potential predisposition for striae.

- CXL through the repositioned flap results in some riboflavin reflux in the dehydrated flap and CXL of the inner-flap collagen and the surface underlying the stroma. This may increase flap-underlying stroma adherence and additionally, potentially reduce or eliminate the inadvertent space created between them (which, in postmortem standard LASIK histopathology, has been shown to be filled with amorphous deposits).

- CXL has well-known disinfection, if not antimicrobial activity; thus, conducting the CXL through a repositioned flap reduces the chance of flap contamination by airborne microorganisms or fomites in the operating room environment, and/or acts as an adjunct disinfectant of the LASIK procedure.

Common to both groups, to avoid any risk of sameday accidental flap contact or rubbing, a bandage planar soft contact lens was then placed on the ocular surface, to be removed the following day. All patients were treated with moxifloxacin (Vigamox; Alcon Laboratories Inc) and $0.1 \%$ dexamethasone/chloramphenicol solution (Dispersadron C; Alcon Laboratories Inc) at least four times a day for 1 week.

\section{Data collection}

All eyes were measured for uncorrected distance visual acuity (UDVA), best (spectacle) corrected distance visual acuity (CDVA), and MRSE via manifest refraction and autorefraction measurements (Speedy-i, K Model Auto Refractometer/Keratometer; Nidek, Gamagori, Japan), visual acuity (Functional Vision Analyzer ${ }^{\mathrm{TM}}$, Stereo Optical Co, Inc., Chicago, IL, USA), corneal topography, for steep and flat keratometry within the $3 \mathrm{~mm}$ radius, employing Placido topography (WaveLight ${ }^{\circledR}$ Allegro Topolyzer ${ }^{\mathrm{TM}}$ Vario $^{\mathrm{TM}}$; Alcon Laboratories Inc) and Scheimpflug imaging (WaveLight ${ }^{\circledR}$ Oculyzer $^{\mathrm{TM}}$ II Diagnostic Device; Alcon Laboratories Inc), and corneal thickness, employing the Oculyzer II and optical coherence tomography (OCT) (RTVue-100; Optovue, Inc, Fremont, CA, USA). ${ }^{20}$

In addition to pachymetry, OCT was employed to provide meridional scans - the hyperreflectivity lines are considered an indirect indication of CXL efficacy, ${ }^{21}$ as demonstrated by our group's study, which showed CXL demarcation lines were evident as late as 3 years postoperatively. ${ }^{22}$ An example of an OCT meridional image scan of a treated cornea is provided in Figure 1 and shows an increased reflectivity of the upper stromal bed. This is supportive of our argument that CXL mainly affects the underlying stroma and not the superjacent flap.

The postoperative evaluation additionally included slitlamp examination, clinical evaluation of dry eye, indications of epithelial ingrowth, ${ }^{23}$ and corneal haze. In addition, we measured endothelial cell counts preoperatively and 1-month postoperatively, employing noncontact specular microscopy (FA-3709; Konan Medical, Irvine, CA, USA).

Postoperative examinations were conducted at 1 day, 1 week, 3 months, 6 months, and up to 1 year. This report presents the refractive and keratometric data analysis from the 1-year follow-up visits. Data were processed using web-based ophthalmic outcome analysis software (IBRA; Zubisoft GmbH, Oberhasli, Switzerland). ${ }^{24}$ Descriptive statistics and analysis were performed using Minitab ${ }^{\circledR}$

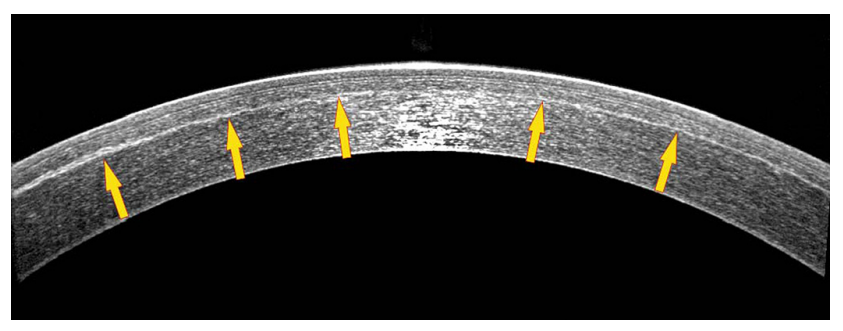

Figure I Anterior-segment optical coherency high-resolution cross-sectional $(6 \mathrm{~mm})$ image of an eye treated with LASIK-CXL for $-2.25 \mathrm{D}$ of sphere and $-0.25 \mathrm{D}$ of astigmatism, obtained I-year postoperatively. Blue arrows indicate the LASIK flap, while yellow arrows indicate the stromal hyper-reflection line, which correlates with the depth of the prophylactic cross-linking effect.

Abbreviations: CXL, cross-linking; LASIK, laser-assisted in situ keratomileusis. 
16.2.3 Statistical Software (Minitab Ltd., Coventry, UK) and Origin Lab 9 (OriginLab Corp, Northampton, MA, USA). $P$-values less than 0.05 were indicative of statistically significant results in this study.

\section{Results}

The 73 eyes included in group A (LASIK-CXL) belonged to 42 female and 31 male patients; of these, 36 eyes were right (OD) and 37 left (OS). The mean patient age at the time of operation was $27.1 \pm 6.0$ (range: 19 to 39) years. Preoperatively, the mean refractive error was sphere $-6.62 \pm 2.12$ (range: -2.50 to -11.50 ) D, cylinder $-0.98 \pm 0.15$ (range: 0.00 to -5.00 ) D, and the MRSE was $-6.58 \pm 1.98$ (range: -2.50 to -11.50$) \mathrm{D}$. Mean preoperative central corneal thickness was $545.96 \pm 33.93$ (range: 474 to 595 ) $\mu \mathrm{m}$ and at 1 -year postoperatively, was $438.11 \pm 28.35$ (range: 414 to 506) $\mu \mathrm{m}$.

The 82 eyes in group B (stand-alone LASIK) belonged to 41 female and 41 male patients; 41 eyes were right (OD) and 41 left (OS). Mean patient age at the time of surgery was $24.9 \pm 5.9$ (range: 18 to 42 ) years. Preoperatively, mean refractive error was sphere $-5.05 \pm 1.74$ (range: -2.50 to -9.50 ) D, cylinder $-0.85 \pm 0.13$ (range: 0.00 to -4.50 ) D, and MRSE $-5.14 \pm 2.34$ (range: -2.50 to -9.50 ) D. Mean preoperative central corneal thickness was $553.51 \pm 19.11$ (range: 503 to 592) $\mu \mathrm{m}$, and 1-year postoperatively, was $452.25 \pm 21.18$ (range: 423 to 510$) \mu \mathrm{m}$.

Demographic and corneal thickness results are also reported in Table 1. No adverse events, including epithelial ingrowth, diffuse lamellar keratitis, postoperative haze, or other complications, were detected in either of the groups. Endothelial cell counts were not statistically different in either group, when compared preoperatively and 1-month postoperatively.

\section{UDVA outcome and stability}

The monocular UDVA outcome (Figure 2) indicates that in the LASIK-CXL group-A, $90.4 \%$ of the eyes had postoperative UDVA 20/20 (1.0 decimal) or better, and $94.5 \%$ had $20 / 25$ (0.8 decimal) or better. In the stand-alone LASIK group, $85.4 \%$ of the eyes had postoperative UDVA better than 20/20 (1.0 decimal), and 89.0\% had better than $20 / 25$ ( 0.8 decimal). The differences between the two groups at the 20/20 and the 20/25 levels were statistically significant $(P=0.042$ and $P=0.037$, respectively).

\section{Efficacy of CDVA}

The gain-loss data (preoperative CDVA versus postoperative UDVA) (Figure 3) indicate that in the LASIK-CXL group, $35.6 \%$ of the eyes were unchanged, $56.2 \%$ gained one Snellen line, and $8.2 \%$ (six eyes) gained two or more Snellen lines. No eye lost any line. In the stand-alone LASIK group, 37.8\% of the eyes were unchanged, $56.1 \%$ gained one Snellen line, and $4.9 \%$ (four eyes) gained two or more lines. Only $1.2 \%$ (one eye) lost one line.

\section{Refractive predictability and accuracy}

The predictability results are presented in the form of linear regression scatterplots (Figure 4), in which the vertical axis corresponds to the achieved MRSE, and the horizontal axis corresponds to the attempted MRSE. The data for the LASIK-CXL group had a coefficient of determination $\left(r^{2}\right)$ of 0.979 , while for the stand-alone group-B, this was 0.970 .

The postoperative MRSE refraction results are presented, within 0.50 D intervals, in Figure 5. In the LASIK-CXL group, MRSE refraction between -0.50 and $0.00 \mathrm{D}$ was achieved in $82.2 \%$ of the eyes, and in the stand-alone group, this was achieved in $81.7 \%$ (no statistically significant difference $[P=0.079])$.

Postoperative refractive astigmatism results, within intervals of $0.50 \mathrm{D}$ representing the accuracy of the cylinder correction, are illustrated in Figure 6. The LASIK-CXL group had a mean preoperative cylinder of $-0.93 \pm 0.04 \mathrm{D}$, while the stand-alone LASIK group had a mean preoperative

Table I Preoperative demographics, including the planned residual stromal thickness, between the two groups

\begin{tabular}{|c|c|c|c|c|c|c|c|c|}
\hline & \multicolumn{4}{|c|}{ Group A (LASIK-CXL): 65 eyes } & \multicolumn{4}{|c|}{ Group B (stand-alone LASIK): 75 eyes } \\
\hline & Age (years) & $\begin{array}{l}\text { Pre-op } \\
\text { CCT }(\mu \mathrm{m})\end{array}$ & $\begin{array}{l}\text { Planned } \\
\text { residual }(\mu \mathrm{m})\end{array}$ & $\begin{array}{l}\text { Post-op } \\
\text { CCT }(\mu \mathrm{m})\end{array}$ & $\begin{array}{l}\text { Age } \\
\text { (years) }\end{array}$ & $\begin{array}{l}\text { Pre-op } \\
\text { CCT }(\mu \mathrm{m})\end{array}$ & $\begin{array}{l}\text { Planned } \\
\text { residual }(\mu \mathrm{m})\end{array}$ & $\begin{array}{l}\text { Post-op } \\
\text { CCT }(\mu \mathrm{m})\end{array}$ \\
\hline Mean & 27.5 & 545.96 & 329.22 & 438.11 & 24.2 & 553.51 & 344.34 & 452.25 \\
\hline Std dev & \pm 6.1 & \pm 33.93 & \pm 32.15 & \pm 28.35 & \pm 5.8 & \pm 19.11 & \pm 20.55 & \pm 21.18 \\
\hline Min & 19 & 474 & 299 & 414 & 18 & 503 & 313 & 423 \\
\hline Max & 39 & 595 & 398 & 506 & 42 & 592 & 408 & 510 \\
\hline
\end{tabular}

Notes: CCT and planned residual stroma were reported in $\mu \mathrm{m}$. Post-op results refer to the I-year results.

Abbreviations: CCT, Central corneal thickness; CXL, cross-linking; LASIK, laser-assisted in situ keratomileusis; Max, maximum; Min, minimum; Std dev, standard deviation. 

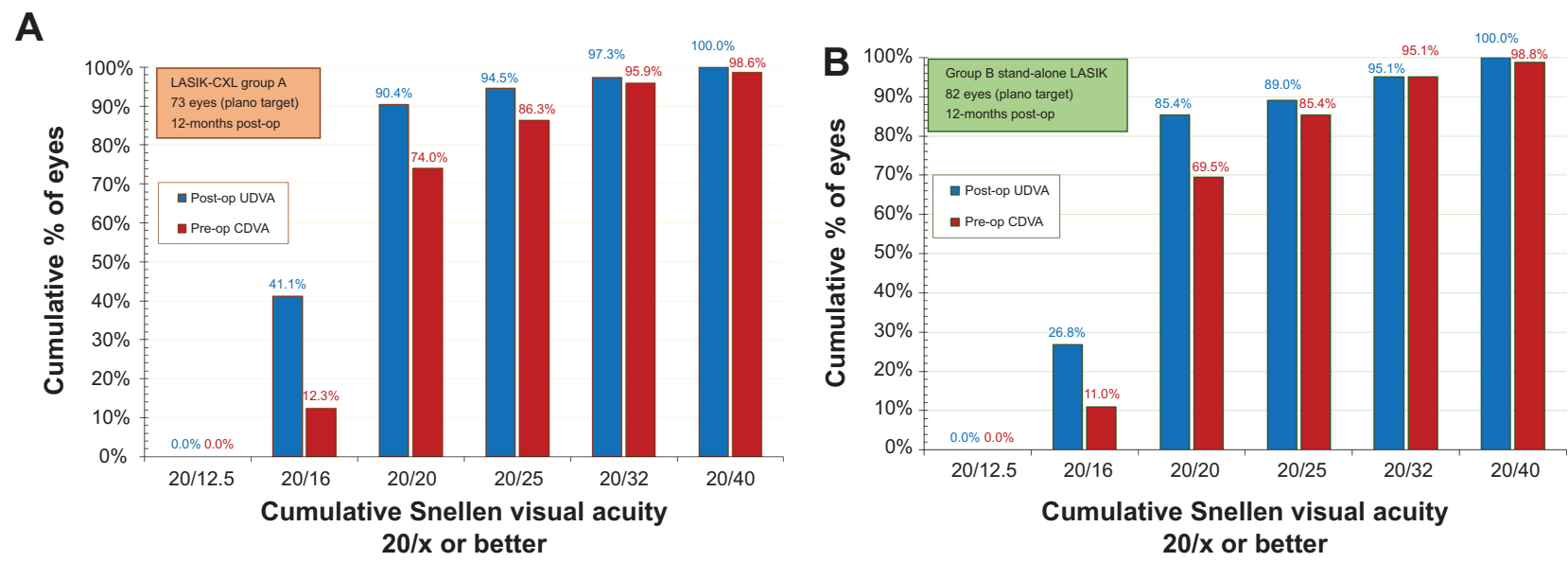

Figure 2 Postoperative uncorrected distance visual acuity (blue columns) versus preoperative corrected distance visual acuity (red columns) I-year postoperatively, in (A) the LASIK-CXL group and (B) the stand-alone LASIK group.

Abbreviations: CDVA, corrected distance visual acuity; CXL, cross-linking; LASIK, laser-assisted in situ keratomileusis; UDVA, uncorrected distance visual acuity.

cylinder of $-0.82 \pm 0.03$ D. The LASIK-CXL group had, postoperatively, $90.4 \%$ of eyes with less than $0.25 \mathrm{D}$ of refractive astigmatism, and mean cylinder of $-0.16 \pm 0.04 \mathrm{D}$. The stand-alone LASIK group had $91.5 \%$ with less than $0.25 \mathrm{D}$ of refractive astigmatism, and mean cylinder of $-0.15 \pm 0.04 \mathrm{D}$.

\section{Refractive and keratometric stability}

Refractive stability was demonstrated by the MRSE correction, as followed during the 1-, 3-, 6-, and 12-month postoperative visits (Figure 7). The 1-year mean postoperative MRSE was $-0.19 \pm 0.17 \mathrm{D}$ in the LASIK-CXL group and $-0.27 \pm 0.23 \mathrm{D}$ in the stand-alone LASIK group. These findings indicate a reduced refractive shift in the LASIK-CXL group in comparison with the stand-alone group $(P=0.063)$. The keratometric stability, demonstrated by the K-flat and

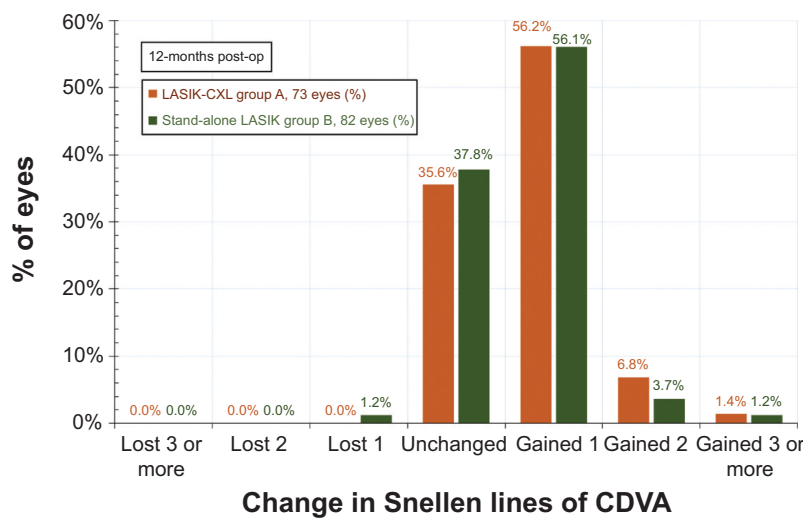

Figure 3 Change in corrected visual acuity, as a percentage of eyes with gain/loss in Snellen lines of corrected distance visual acuity I-year postoperatively.

Abbreviations: CDVA, corrected distance visual acuity; CXL, cross-linking; LASIK, laser-assisted in situ keratomileusis.
$\mathrm{K}$-steep average values up to the 1-year postoperative visit, is illustrated in Figure 8. The results indicate an increased keratometric stability in the LASIK-CXL group (1-year at $+0.03 \mathrm{D}$ in the flat and $+0.05 \mathrm{D}$ in the steep compared
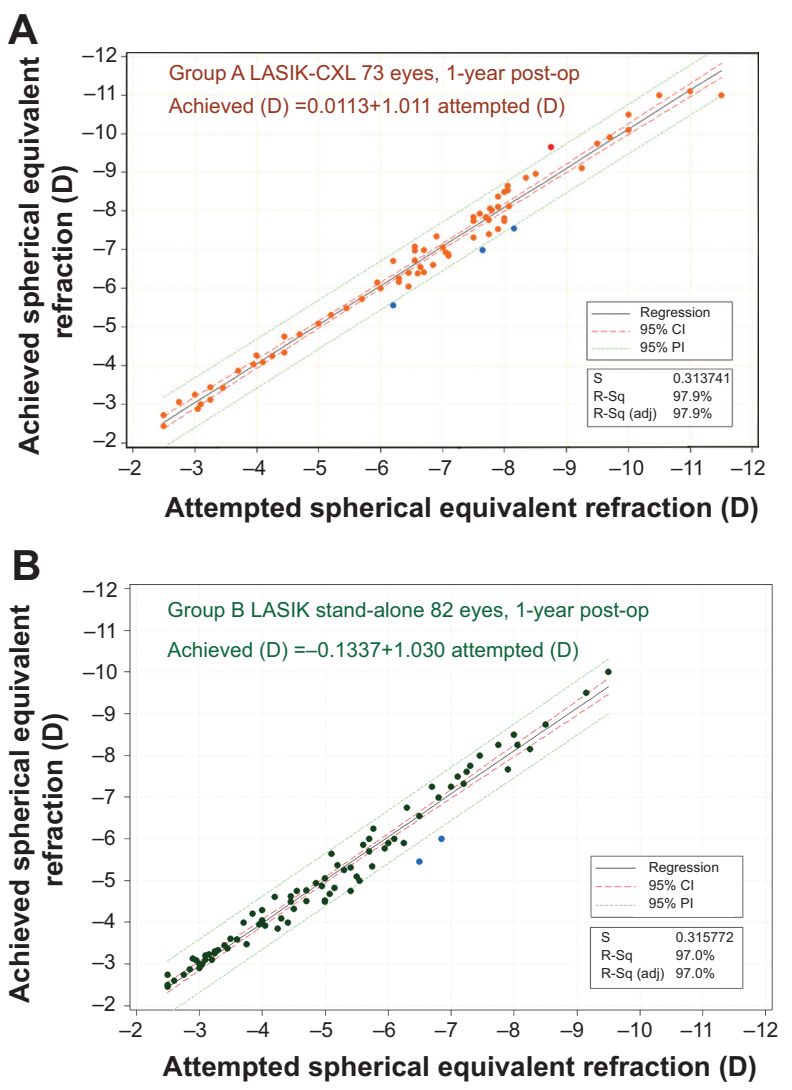

Figure 4 Predictability of spherical equivalent correction, measured at I-year postoperatively, showing achieved spherical equivalent (vertical axis) versus attempted spherical equivalent (horizontal axis), in (A) the LASIK-CXL group and (B) the stand-alone LASIK group.

Abbreviations: CDVA, corrected distance visual acuity; $\mathrm{Cl}$, confidence interval; $\mathrm{CXL}$, cross-linking; PI, prediction interval; $\mathrm{S}$, sum of residuals; $\mathrm{R}$-sq, coefficient of determination; R-sq (adj), adjusted coefficient of determination. 


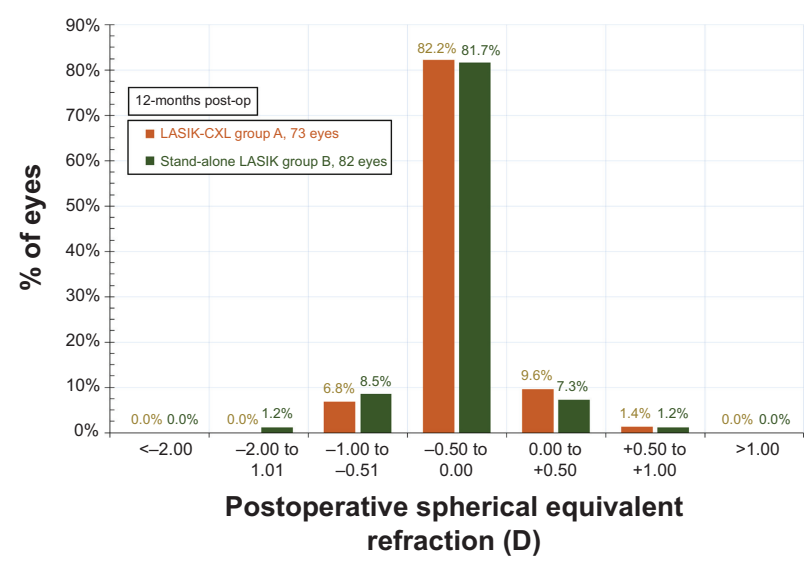

Figure 5 Postoperative spherical equivalent refraction for both groups, I-year postoperatively.

Abbreviations: CXL, cross-linking; LASIK, laser-assisted in situ keratomileusis.

with the 1-month baseline) compared with the stand-alone LASIK group ( $+0.67 \mathrm{D}$ and $+0.55 \mathrm{D}$, respectively), which was statistically significant $(P=0.039)$.

\section{Discussion}

Improved diagnostics, ablation profiles, and laser-beam tracking refinements of the LASIK procedure, ${ }^{25}$ and improvements attributed to femtosecond laser-assisted flap creation $^{26-28}$ all have contributed to an excellent track record in myopia correction.

However, refractive regression in high myopic corrections, remains a possibility. There are several possible mechanisms leading to post-LASIK regression. For example, a correlation between increased epithelial thickness and myopia correction up to 1-year postoperatively was noted, in a study by Spadea et $\mathrm{a}^{29}$ in high-myopic (myopias between -8.50 and $-12.25 \mathrm{D})$ patients. This epithelial thickening in high myopia has been corroborated recently in femtosecond LASIK correction of high myopia. ${ }^{30}$ Furthermore, a comparison of stand-alone LASIK to LASIK-CXL in high myopia verified that the observed post-LASIK epithelial thickening changes are significantly less prominent in LASIK-CXL cases. This difference may correlate with higher regression rates and/or may depict increased biomechanical instability in stand-alone LASIK. ${ }^{31}$ We believe that this finding is a manifestation of the same aspect, which is the chief difference between the two groups - the application of preventive CXL in this group. As we have previously demonstrated, ${ }^{32} \mathrm{CXL}$ affects epithelial thickness, leading to reduced overall thickness.

In the present study, we investigated up to 1-year postoperative refractive and stability results of 155 eyes subjected to femtosecond-laser LASIK for myopia between two groups - group A in which prophylactic high-fluence CXL was incorporated and group B that received stand-alone LASIK. The two groups in the study were by all other means matched: ablation zone, flap thickness, surgeon, lasers employed, and postoperative medication and treatment. Our research on this subject matter is ongoing, and we do hope to report long-term follow-up results in the future.

The postoperative evaluation in the LASIK-CXL group did not indicate clinical or topographic evidence of complications in comparison with the stand-alone group. Visual rehabilitation between the two groups, as expressed by CDVA and contrast sensitivity evaluation, was at similar levels, without induction of side effects or compromise of visual safety. The refractive outcome, predictability, and stability were completely satisfactory, and in some cases superior to standard LASIK (for example, data shown in in Figure 2, subgroup of achieved visual acuity of 20/16).
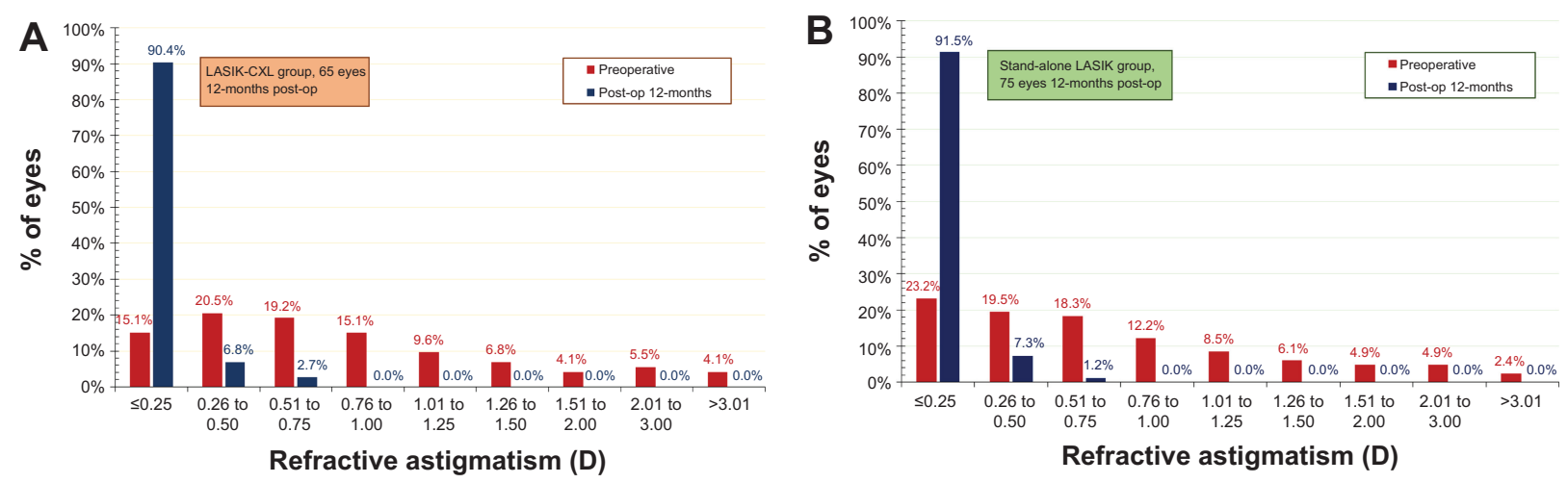

Figure 6 Refractive astigmatism preoperatively (red columns) and I-year postoperatively (blue columns), in (A) the LASIK-CXL group and (B) the stand-alone LASIK group.

Notes: The graph shows percentage of eyes (vertical axis) versus refractive astigmatism (horizontal axis).

Abbreviations: CXL, cross-linking; LASIK, laser-assisted in situ keratomileusis. 


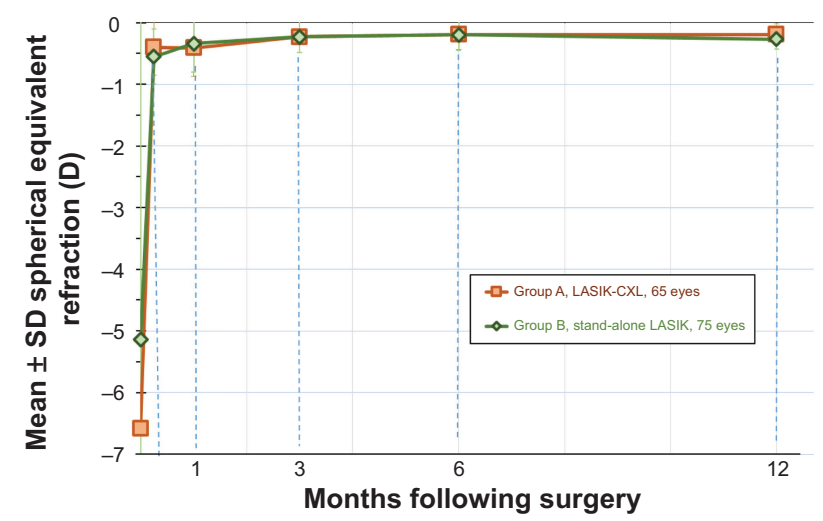

Figure 7 Stability of manifest spherical equivalent refraction for both groups, expressed in diopters (D), up to I-year postoperatively.

Abbreviations: CXL, cross-linking; LASIK, laser-assisted in situ keratomileusis; SD, standard deviation.

Comparison of the stability results between the two groups indicates that in the stand-alone group, there was a slight positive slope in the keratometric readings, both at the flat and the steep meridian, as illustrated in Figure 8, which is suggestive of a mild progressive corneal steepening. The recorded changes correspond to $+0.67 \mathrm{D}$ for the flat meridian and $+0.54 \mathrm{D}$ for the steep meridian. The data clearly show a trend toward mild corneal steepening in the long-term postoperative period. A similar refractive shift has been reported previously by our team in LASIK corrections of high myopia with no prophylactic CXL application. ${ }^{11}$

There was no such trend of keratometric shift in the LASIK-CXL group (+0.03 D and +0.05 respectively). Other differences between the two groups were the slightly increased stability of the MRSE (Figure 7), as well as the improved predictability (Figure 4), despite the larger range of attempted correction and increased preoperative astigmatism
(Figure 6). It is worth noting that the mean spherical error $(\mathrm{S})$, as well as cylinder error $(\mathrm{C})$ treated in group $\mathrm{A}$ (mean $\mathrm{S}$ $-6.62 \mathrm{D}$, maximum $\mathrm{S}-11.50 \mathrm{D}$; mean $\mathrm{C}-1.35 \mathrm{D}$, maximum $\mathrm{C}-5.25 \mathrm{D}$ ) was significantly greater than in the LASIK standalone group (mean $\mathrm{S}-5.05 \mathrm{D}$, maximum $\mathrm{S}-9.50 \mathrm{D}$; mean $\mathrm{C}-0.85 \mathrm{D}$, maximum $\mathrm{C}-3.50 \mathrm{D})$. Despite the apparently more challenging cases included in group A (LASIK-CXL) compared to group B (Standard-LASIK), the refractive results in the LASIK-CXL group were equally good and, in some cases, slightly better.

One aspect that needs consideration is the possibility of refractive flattening as a result of the CXL applied. Our clinical experience, as well as the peer-review literature, suggests the continued progression of the CXL effect over time. ${ }^{33}$ We have indicated that the long-term keratometry flattening progression in the fully cross-linked corneas is of the order of $-0.30 \mathrm{D}$. One has to acknowledge the following two parameters that differentiate this finding, when considering the LASIK-CXL:

- The keratoconus management cases were fundamentally unstable ectatic corneas, whereas in the present work only healthy corneas were included, and

- The keratoconus management cases received the "full energy" treatment (up to $6 \mathrm{~J} / \mathrm{cm}^{2}$ ), whereas in the present work, the LASIK-CXL eyes received only a "partial energy" treatment $\left(2.4 \mathrm{~J} / \mathrm{cm}^{2}\right)$, corresponding to less than half of the standard protocol energy.

It may thus be estimated that the possibility of long-term keratometric flattening may well be restricted. Additional long-term studies are required to investigate this aspect.

In view of the expressed skepticism by colleagues regarding possible regression of the refractive effect, ${ }^{34}$ sometimes, despite low preoperative risk (for example, classified as low
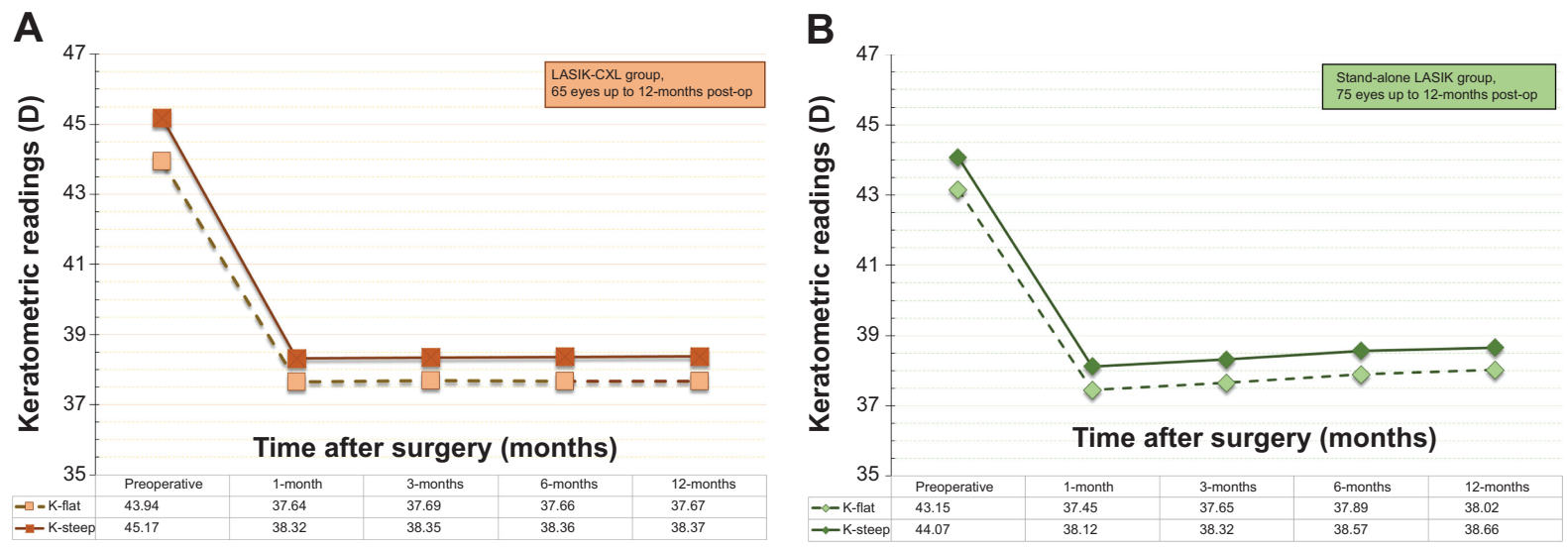

Figure 8 Stability of corneal keratometry for (A) the LASIK-CXL group and (B) the stand-alone LASIK group, expressed in diopters (D), up to I-year postoperatively. Abbreviations: CXL, cross-linking; LASIK, laser-assisted in situ keratomileusis. 
risk in the Ectasia Risk Score System), ${ }^{35}$ caution has been recommended when LASIK was performed in cases of high myopia with a thin residual stromal bed. ${ }^{36}$

Our team has performed and reported a large number of successful LASIK-CXL procedures over the last 8 years, and we view this prophylactic treatment as a pivotal biomechanical enhancement of the LASIK procedure - in a young adult, in any patient under the age of 30 years with high myopia and/or astigmatism, and any patient with a difference of over $0.50 \mathrm{D}$ in the amount of the astigmatism between the two eyes. In our opinion, it does not merit "leniency" with preoperative form-fruste keratoconus criteria. All cases studied in this work, as well as in previous reports by our group, have been screened thoroughly for any signs of tomographic cornea irregularity.

\section{Conclusion}

LASIK combined with a prophylactic CXL intervention appears to provide predictability as well as refractive and keratometric stability. The data reported in this study provide evidence of the safety and efficacy of this approach. The adjuvant CXL procedure adds enhanced corneal biomechanical stability. High-myopic and younger age LASIK cases, may require biomechanical re-enforcement, as means of reducing the incidence and degree of future myopic regression and/or the potential ectasia risk.

\section{Author contributions}

AJK design and conduct of the study, and collection and interpretation of the data. AJK performed data management, and CK and GA analyzed the data. AJK, CK and GA prepared the manuscript and AJK, CK, and GA participated in manuscript review. All authors provided manuscript approval.

\section{Disclosure}

AJK has held consultant or advisory positions with Alcon/ WaveLight, Allergan, Avedro, and i-Optics. The other authors report no other conflicts of interest in this work.

\section{References}

1. Solomon KD, Fernández de Castro LE, Sandoval HP, et al; Joint LASIK Study Task Force. LASIK world literature review: quality of life and patient satisfaction. Ophthalmology. 2009;116(4):691-701.

2. Shortt AJ, Allan BD, Evans JR. Laser-assisted in-situ keratomileusis (LASIK) versus photorefractive keratectomy (PRK) for myopia. Cochrane Database Syst Rev. 2013;1:CD005135.

3. Shortt AJ, Bunce C, Allan BD. Evidence for superior efficacy and safety of LASIK over photorefractive keratectomy for correction of myopia. Ophthalmology. 2006;113(11):1897-1908.
4. Liu Z, Li Y, Cheng Z, Zhou F, Jiang H, Li J. Seven-year follow-up of LASIK for moderate to severe myopia. J Refract Surg. 2008;24(9): 935-940.

5. Güell JL, Muller A. Laser in situ keratomileusis (LASIK) for myopia from -7 to -18 diopters. J Refract Surg. 1996;12(2):222-228.

6. Oruçoğlu F, Kingham JD, Kendüşim M, Ayoğlu B, Toksu B, Göker S. Laser in situ keratomileusis application for myopia over minus 14 diopter with long-term follow-up. Int Ophthalmol. 2012;32(5):435-441.

7. Magallanes R, Shah S, Zadok D, et al. Stability after laser in situ keratomileusis in moderately and extremely myopic eyes. $J$ Cataract Refract Surg. 2001;27(7):1007-1012.

8. Chayet AS, Assil KK, Montes M, Espinosa-Lagana M, Castellanos A, Tsioulias G. Regression and its mechanisms after laser in situ keratomileusis in moderate and high myopia. Ophthalmology. 1998;105(7): 1194-1199.

9. Alió JL, Muftuoglu O, Ortiz D, et al. Ten-year follow-up of laser in situ keratomileusis for myopia of up to -10 diopters. Am JOphthalmol. 2008;145(1):46-54.

10. Chen YI, Chien KL, Wang IJ, et al. An interval-censored model for predicting myopic regression after laser in situ keratomileusis. Invest Ophthalmol Vis Sci. 2007;48(8):3516-3523.

11. Kanellopoulos AJ, Asimellis G. Refractive and keratometric stability in high myopic LASIK with high-frequency femtosecond and excimer lasers. J Refract Surg. 2013;29(12):832-837.

12. Binder PS. Analysis of ectasia after laser in situ keratomileusis: risk factors. J Cataract Refract Surg. 2007;33(9):1530-1538.

13. Randleman JB. Post-laser in-situ keratomileusis ectasia: current understanding and future directions. Curr Opin Ophthalmol. 2006; 17(4):406-412.

14. Kanellopoulos AJ. Long-term safety and efficacy follow-up of prophylactic higher fluence collagen cross-linking in high myopic laser-assisted in situ keratomileusis. Clin Ophthalmol. 2012;6:1125-1130.

15. Celik HU, Alagöz N, Yildirim Y, et al. Accelerated corneal crosslinking concurrent with laser in situ keratomileusis. J Cataract Refract Surg. 2012;38(8):1424-1431.

16. Kanellopoulos AJ, Pamel GJ. Review of current indications for combined very high fluence collagen cross-linking and laser in situ keratomileusis surgery. Indian J Ophthalmol. 2013;61(8):430-432.

17. Kanellopoulos AJ, Asimellis G. Digital analysis of flap parameter accuracy and objective assessment of opaque bubble layer in femtosecond laser-assisted LASIK: a novel technique. Clin Ophthalmol. 2013; 7:343-351.

18. Kanellopoulos AJ, Asimellis G. Long-term bladeless LASIK outcomes with the FS200 Femtosecond and EX500 Excimer Laser workstation: the Refractive Suite. Clin Ophthalmol. 2013;7:261-269.

19. Mi S, Dooley EP, Albon J, Boulton ME, Meek KM, Kamma-Lorger CS. Adhesion of laser in situ keratomileusis-like flaps in the cornea: Effects of crosslinking, stromal fibroblasts, and cytokine treatment. J Cataract Refract Surg. 2011;37(1):166-172.

20. Kanellopoulos AJ, Asimellis G. Comparison of high-resolution Scheimpflug and high-frequency ultrasound biomicroscopy to anteriorsegment OCT corneal thickness measurements. Clin Ophthalmol. 2013; 7:2239-2247.

21. Seiler T, Hafezi F. Corneal cross-linking-induced stromal demarcation line. Cornea. 2006;25(9):1057-1059.

22. Kanellopoulos AJ, Asimellis G. Introduction of quantitative and qualitative cornea optical coherence tomography findings induced by collagen cross-linking for keratoconus: a novel effect measurement benchmark. Clin Ophthalmol. 2013;7:329-335.

23. Henry CR, Canto AP, Galor A, Vaddavalli PK, Culbertson WW, Yoo SH. Epithelial ingrowth after LASIK: clinical characteristics, risk factors, and visual outcomes in patients requiring flap lift. $J$ Refract Surg. 2012;28(7):488-492.

24. Zuberbuhler B, Galloway P, Reddy A, Saldana M, Gale R. A webbased information system for management and analysis of patient data after refractive eye surgery. Comput Methods Programs Biomed. 2007;88(3):210-216. 
25. Maldonado MJ, Nieto JC, Piñero DP. Advances in technologies for laser-assisted in situ keratomileusis (LASIK) surgery. Expert Rev Med Devices. 2008;5(2):209-229.

26. Vestergaard A, Ivarsen A, Asp S, Hjortdal JØ. Femtosecond (FS) laser vision correction procedure for moderate to high myopia: a prospective study of ReLEx $\left({ }^{\circledR}\right)$ flex and comparison with a retrospective study of FSlaser in situ keratomileusis. Acta Ophthalmol. 2013;91(4):355-362.

27. Kymionis GD, Kankariya VP, Plaka AD, Reinstein DZ. Femtosecond laser technology in corneal refractive surgery: a review. J Refract Surg. 2012;28(12):912-920.

28. Kanellopoulos AJ, Asimellis G. Three-dimensional LASIK flap thickness variability: topographic central, paracentral and peripheral assessment, in flaps created by a mechanical microkeratome (M2) and two different femtosecond lasers (FS60 and FS200). Clin Ophthalmol. 2013;7:675-683.

29. Spadea L, Fasciani R, Necozione S, Balestrazzi E. Role of the corneal epithelium in refractive changes following laser in situ keratomileusis for high myopia. J Refract Surg. 2000;16(2):133-139.

30. Kanellopoulos AJ, Asimellis G. Longitudinal postoperative LASIK epithelial thickness profile changes in correlation with degree of myopia correction. J Refract Surg. 2014;30(3):166-171.

31. Kanellopoulos AJ, Asimellis G. Epithelial remodeling after femtosecond laser-assisted high myopic LASIK: comparison of stand-alone with LASIK combined with prophylactic high-fluence cross-linking. Cornea. 2014;33(5):463-469.
32. Kanellopoulos AJ, Aslanides IM, Asimellis G. Correlation between epithelial thickness in normal corneas, untreated ectatic corneas, and ectatic corneas previously treated with CXL; is overall epithelial thickness a very early ectasia prognostic factor? Clin Ophthalmol. 2012;6:789-800.

33. Kanellopoulos AJ, Asimellis G. Keratoconus management: longterm stability of topography-guided normalization combined with high-fluence CXL stabilization (the Athens Protocol). J Refract Surg. 2014;30(2):88-93.

34. Ambrósio R, Dawson DG, Salomão M, Guerra FP, Caiado AL, Belin MW. Corneal ectasia after LASIK despite low preoperative risk: tomographic and biomechanical findings in the unoperated, stable, fellow eye. J Refract Surg. 2010;26(11):906-911.

35. Randleman JB, Trattler WB, Stulting RD. Validation of the Ectasia Risk Score System for preoperative laser in situ keratomileusis screening Am J Ophthalmol. 2008;145(5):813-818.

36. Spadea L, Cantera E, Cortes M, Conocchia NE, Stewart CW. Corneal ectasia after myopic laser in situ keratomileusis: a long-term study. Clin Ophthalmol. 2012;6:1801-1813.
Clinical Ophthalmology

\section{Publish your work in this journal}

Clinical Ophthalmology is an international, peer-reviewed journal covering all subspecialties within ophthalmology. Key topics include: Optometry; Visual science; Pharmacology and drug therapy in eye diseases; Basic Sciences; Primary and Secondary eye care; Patien Safety and Quality of Care Improvements. This journal is indexed on

Submit your manuscript here: http://www.dovepress.com/clinical-ophthalmology-journa

\section{Dovepress}

PubMed Central and CAS, and is the official journal of The Society of Clinical Ophthalmology (SCO). The manuscript management system is completely online and includes a very quick and fair peer-review system, which is all easy to use. Visit http://www.dovepress.com/ testimonials.php to read real quotes from published authors. 